\title{
Educação e gênero: histórias de estudantes do curso Gênero e Diversidade na Escola
}

\author{
Leandro Castro Oltramari \\ 0000-0002-9610-0502 \\ Marivete Gesser $^{1}$ \\ 0000-0002-4091-9754 \\ 'Universidade Federal de Santa Catarina, Florianópolis, UFSC, Brasil. 88040-900
}

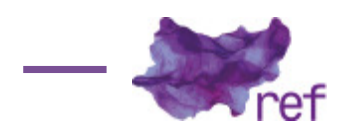

Resumo: O objetivo do trabalho foi o de identificar as contribuições do curso de Formação de Professores em Gênero e Diversidade na Escola (GDE) para os profissionais da educação básica. Para tanto, foi realizado um grupo focal com nove participantes do curso, sendo oito mulheres e um homem. Os dados foram analisados com base na análise de conteúdo. Os resultados mostraram que o curso contribuiu para: a aquisição de conhecimentos sobre os marcadores sociais das diferenças e compreensão desses como sociais e políticos; o reconhecimento e posicionamento das participantes como feministas; a ressignificação de experiências profissionais e de vida relacionadas às temáticas do GDE. As entrevistadas destacaram a relevância de temas como gênero, sexualidade, raça, geração, religião e deficiência na formação de professores.

Palavras-chave: educação; gênero; diversidade; formação.

Education and gender: student stories from the Gender and Diversity course in School Abstract: The objective of this work was to identify the contributions of the Teacher Training Course in Gender and Diversity in School (GDE) for primary education professionals. Therefore, a focal group with nine participants of the course was carried out, being eight women and one man. Data were analyzed based on content analysis. The results showed that the course contributed to: the acquisition of knowledge about social markers of differences and understanding of these as social and political; the recognition and positioning of participants as feminists; the re-signification of professional and life experiences related to the themes of the DGE. The interviewees highlighted the relevance of themes such as gender, sexuality, race, generation, religion and inadequacy in teacher training.

Keywords: Education; Gender; Diversity; Formation.

\section{Introdução}

As temáticas de gênero e sexualidade na escola têm despertado muitas discussões não somente pela relevância que têm ocupado nas escolas, mas principalmente em virtude das pressões realizadas recentemente no Congresso Nacional que retirou do Plano Nacional de Educação todas as expressões referentes a gênero e orientação sexual, o que gerou um efeito "cascata" em outros planos estaduais e municipais (Raquel GREBINSKY, 2016). No entanto, essa discussão não é recente; já existem muitos estudos que afirmam a importância dos estudos de gênero e sexualidade no contexto escolar.

Paulo CABRAL (2016) destaca a importância dos trabalhos sobre os direitos humanos, especificamente no que tange às discussões de gênero e à diversidade sexual. Os autores apontam que a escola tem um compromisso ético-político pautado no respeito e acolhimento a essa diversidade.

Cabe também destacar que a concepção moral/religiosa e a heteronormatividade estão muito presentes nas falas das/os professores/as entrevistadas/os (Marivete GESSER; Leandro 
OLTRAMARI; Gelson PANISSON, 2015; Fabiane SILVA, 2016) e fazem com que muitas vezes, a partir delas, os professores respondam as situações relacionadas com as questões de gênero e sexualidade pautados em suas experiências culturais e pessoais imediatas, deixando de lado considerações científicas e político-pedagógicas sobre o tema (Ana MADUREIRA; Ângela BRANCO, 2015). A pesquisadora Maria Eulina Pessoa de CARVALHO (2010) aponta que a categoria de gênero não é de fácil compreensão, pois está imbricada com o que ela relacionou ao conceito de habitus de Pierre Bourdieu, ou seja, a categoria de gênero se faz a partir de uma estrutura que se mantém de alguma maneira e configura um tipo de visão sobre a diferença entre os sexos e uma divisão social e de poder entre eles, que é mantida a partir das práticas sociais.

Dessa maneira, podemos pensar que essas experiências culturais que, de alguma forma, categorizam os "normais" e "aqueles que não o são" produzem aquilo que Zulmira BORGES e Dagmar MEYER (2008) chamaram de "pânico moral", conceito desenvolvido originalmente por Jeffrey Weeks que se caracteriza como um fenômeno que faz com que professores evitem falar ou mesmo abordar o tema, pois isto colocaria em questionamento sua orientação sexual, além de a publicização dessas temáticas ser considerada como algo que poderia "influenciar" estudantes mais jovens.

Para o enfrentamento dessas questões que são relativas às dificuldades de debater temas como gênero e sexualidade na escola, as pesquisas que abordam tais temáticas e preconizam a formação de professores têm sido fundamentais para contribuir com o enfrentamento dessas problemáticas e com a construção de processos educativos inclusivos. Assim, existem muitos autores que abordam a importância da formação de professores para a superação das discriminações de gênero na escola (Nilson DINIS, 2008; GESSER; OLTRAMARI, Adriano NUERNBERG; Denise CORD; 2012; Mareli GRAUPE, 2013; Helena ALTMANN, 2013; SILVA, 2016).

Para autores como Dinis (2008), as formações com professores devem buscar romper com as dicotomias binárias das sexualidades como homossexualidade-heterossexualidade, masculinidade-feminilidade e problematizar tanto as linguagens científicas quanto as representações que os discentes possuem sobre o assunto.

Outra questão fundamental apontada por Altmann (2013) é referente à importância da discussão das temáticas de gênero e diversidade sexual na formação universitária que, por ter maior autonomia, dá-se ao direito de não fazê-la, caso considere pertinente. A autora destaca que a omissão do tema na formação inicial dos professores ocasiona futuros profissionais docentes despreparados para lidarem com esta temática.

Graupe (2013) aponta que a formação de professores deve focar o combate às práticas discriminatórias e homofóbicas e que os cursos de formação de professores, para a construção de uma escola mais democrática e inclusiva, devem se pautar sobre estas temáticas. Este é, para a autora, um dos grandes desafios da escola e, consequentemente, das formações de professores. Ela aponta o curso Gênero e Diversidade na Escola como uma dessas importantes estratégias.

\section{Gênero e Diversidade na Escola: uma política para a formação de professoras}

Visando ao estudo das políticas públicas educacionais relacionadas a gênero e sexualidade, Cláudia VIANNA (2012) analisou documentos e identificou que, nos primeiros anos do Governo Lula, as pautas dos movimentos LGBTT foram, não sem dificuldades, incorporadas à agenda pública daquele Governo. A partir desta agenda, houve um incremento das políticas relacionadas à temática da diversidade, sendo essas principalmente incentivadas a partir de diversas secretarias criadas com estes fins, as quais desenvolveram ações de combate ao preconceito e à discriminação no campo da educação.

Luis MELLO, Walderes BRITO e Daniela MAROJA (2012) apontam o Programa de Formação de Professores em Gênero e Diversidade na Escola como uma importante política pública voltada ao combate do preconceito e da discriminação às populações LGBT no campo da educação. Os autores e a autora indicam que as políticas públicas para as populações LGBT, mesmo com os avanços do Governo Lula, foram quase inexistentes, principalmente em relação aos quesitos referentes ao combate à homofobia e à garantia de direitos às populações LGBT. Ademais, essas ações ficaram restritas ao caráter programático, sem força constitucional, o que ocorreu sobretudo devido às dificuldades encontradas no parlamento conservador brasileiro.

O curso de Formação de Professores em Gênero e Diversidade na Escola foi uma proposta de formação de professores que objetivou oferecer, de modo continuado, uma formação sobre as temáticas gênero, diversidade na escola, relações étnico-raciais, sexualidade e orientação sexual. O curso foi resultado de uma parceria entre a Secretaria Especial de Política para as Mulheres e a Secretaria Especial de Políticas de Promoção da lgualdade Racial, além da Secretaria de Educação a Distância do MEC, a Secretaria de Educação Continuada, Alfabetização e Diversidade e do Centro Latino-Americano em Sexualidade e Direitos Reprodutivos da UERJ (Nilcéa FREIRE; Edson SANTOS; Fernando HADDAD, 2012). 
O curso foi realizado como piloto em 2006 pela UERJ e, posteriormente, em várias universidades do Brasil. Na Universidade Federal de Santa Catarina (UFSC) houve três edições até 2016, sendo duas delas na modalidade de extensão e uma como Especialização Lato Sensu.

Na última versão do GDE oferecida pela UFSC, na modalidade de Curso de Especialização, houve a inserção das temáticas "religiosidade" e "deficiência", o que deu ao curso um caráter inovador. Assim, essas temáticas também puderam ser problematizadas, ampliando-se o olhar para as questões relacionadas à diversidade na escola.

Várias pesquisas foram realizadas sobre a implementação desses cursos. Existem diversas pesquisas sobre GDE em São Paulo (Célia ROSSI; Carla VILARONGA; Osmar GARCIA; Maria LIMA, 2012; Ana Paula VENCATO, 2014); Goiás (Sulivan BARROS, 2017); Distrito Federal (Jaqueline BARBOSA, 2014); Santa Catarina (GRAUPE; Miriam GROSSI, 2014); Rio Grande do Sul (Fabiane TEIXEIRA, 2014); Paraíba (Ana Cristina ROSA, 2016); Paraná (Renata TOZETTI, 2017); uma obra organizada por Andrea KAMENSKY, Jonas WAKS, Silmara CONCHÃO e Zilda SILVA (2016) que possui textos sobre a experiência de vários outros estados, além de uma pesquisa nacional sobre a avaliação dos processos e resultados e os impactos do Projeto (Sérgio CARRARA; Marcos NASCIMENTO; Aline DUQUE; Lucas TRAMONTANO; Maria Elisabete PEREIRA, 2017).

Essas pesquisas realizadas com os professores que participaram como cursistas no GDE têm demonstrado que a formação de professores pelo GDE produziu um efeito que foi além da própria escola. Eles tiveram a capacidade e a possibilidade de discutir e perceber suas próprias experiências a partir do referencial crítico que o próprio curso forneceu (ROSSI; VILARONGA; GARCIA; LIMA, 2012).

Apesar disso, em alguns estudos também se destaca que as transformações discursivas não produzem mudança na instituição escola de imediato. As autoras do estudo acima citado observaram relatos de cursistas cujas histórias de vida muitas vezes produziam conflitos com os conteúdos gerados e disseminados no curso, o que elas chamaram de "equívocos conceituais" construídos pelas cursistas fora da escola (ROSSI; VILARONGA; GARCIA; LIMA, 2012; BARROS, 2017).

Segundo Barros (2017), essas tensões decorrentes dos conteúdos do curso foram trazidas pelas estudantes, inclusive durante o período em que estavam cursando os módulos do GDE. Identificou-se, a partir de suas histórias de vida, que ao mesmo tempo que os conteúdos vinham para a cena, vinham também as memórias e as reflexões. As histórias "generificadas" das cursistas passaram pela escola e por sua vida pessoal e de alguma forma foram reelaboradas por algumas delas.

É importante compreender as pesquisas que abordam a experiência do significado dos cursos para os estudantes do GDE. Em trabalho de doutorado de Barbosa (2014), a autora revela que, de maneira geral, os professores cursistas realçaram a validade do curso e consideraram-no uma importante ação das políticas públicas. Ao mesmo tempo, ressaltaram a dificuldade nas execuções das ações nas escolas devido à complexidade dos assuntos abordados e à falta de apoio da direção, de colegas e ainda da religiosidade que se estabelece de forma muito "fundamentalista" - segundo os entrevistados. Além disso, as cursistas reclamaram da formação que tiveram em suas graduações. Ademais, destacaram que os conhecimentos adquiridos nos cursos de graduação não são suficientes para mudar as práticas em sala de aula (GRAUPE; GROSSI, 2014).

Ainda em pesquisa com cursistas de um curso de aperfeiçoamento do GDE, Graupe e Grossi (2014) identificaram que existe uma necessidade de "sensibilizar" os professores sobre as categorias que são abrangidas pelo curso, de modo que essas possam ser debatidas e problematizadas. Todavia, as autoras ressaltaram que somente a sensibilização não é o suficiente e que existe a urgência de uma mudança de paradigma no interior da escola. Um fato que chama atenção é que nesta pesquisa se identificou que as cursistas escolheram o curso "justamente para ampliar seus conhecimentos e conseguir argumentar e se posicionar perante a direção da escola, alun@s e famílias sobre a importância e a necessidade de trabalhar essas temáticas no cotidiano escolar" (p. 117). Ou seja, essas pessoas já se mostravam talvez sensibilizadas à temática quando entraram no curso. As professoras procuraram o curso para ter uma formação mais aprofundada sobre o tema. As autoras apontam, ainda, para a relevância da formação desses profissionais, ressaltando que "as competências de relações de gênero e diversidade proporcionam discussões sobre os estereótipos que estão, de forma consciente ou inconsciente, presentes nas práticas educativas [...]" (p. 124). Por fim, as autoras apontam para a importância de que as "profissionais da educação articulem a discussão das questões de gênero, sexualidades, diversidade e relações étnico-raciais, considerando a esfera da vida privada, política e profissional" (p. 123).

Sobre a discussão da formação subjetiva do professor, como indicam acima Graupe e Grossi (2014), a pesquisa de Melissa BELLO e Dayana SANTOS (2010) é muito intrigante, pois elas avaliaram, através de questionário, os estudantes e seus projetos de intervenção, cuja solicitação era de que fossem realizados no fim do GDE. Foi interessante constatar que, apesar de um número 
significativo de estudantes avaliar que o curso foi útil para sua atualização de conhecimentos sobre a área e formação em gênero, seus projetos, de forma consistente, ainda trabalhavam a temática de forma pontual e muitas vezes reproduzindo elementos que o próprio curso questionava. A constatação de Bello e Santos (2010) tem sido alvo de pesquisas sobre formação de professores.

Tais reflexões têm sido abordadas a partir dos chamados "saberes docentes" (Marli ZIBETTI; Marilene SOUZA, 2007). As autoras compreendem que esses saberes docentes, que não são necessariamente científicos, formam parte considerável do fazer desses profissionais e interferem diretamente em sala de aula.

Segundo Juliana LOPES, Lucia PULINO, Regina BARBATO e Regina PEDROZA (2016), muitas vezes os cursos de formação de professores abrem pouco espaço para diálogo, e problematizam muito pouco esses saberes. Assim, professores que possuem saberes prévios muito arraigados, sejam eles quais forem, podem expressar dificuldades de abertura para conhecimentos que se contrapõem a essas certezas. Dessa forma, podem não conseguir intervir de uma maneira adequada com as propostas teórica e metodológica de um programa proposto.

Rosa (2016), em sua pesquisa sobre a formação dada pelo GDE na Paraíba, apresenta dados que demonstram que o curso e, mais especificamente, a disciplina de Gênero, foram fundamentais para a ampliação e a ressignificação daquilo que é chamado de saberes prévios. Em seu estudo, apontou que as professoras apresentavam uma apreensão sobre os conhecimentos de gênero bem conservadora pela forma binária com que socialmente essas diferenças são experienciadas. Essas vivências, muitas vezes, foram relatadas de forma conflitiva e isso trouxe sofrimento às/aos participantes. As/os participantes da pesquisa relataram que, de uma forma mais pontual ou de forma sistemática, esses conhecimentos foram úteis para uma transformação de suas concepções e em suas intervenções em salas de aula, e que o curso apresentou uma forte importância no combate às desigualdades de gênero.

Carrara et al. (2017), com o intuito de avaliar os cursos Gênero e Diversidade na Escola no âmbito nacional visando, também e entre outras coisas, à identificação do que levou os participantes a se inscreverem no curso, identificaram que $53 \%$ dos participantes se inscreveram com o intuito de "ter mais ferramentas para atuar no meu campo de trabalho", $23 \%$ "ter formação complementar e melhorar meu currículo" (p. 42). Quanto à avaliação do curso pelas cursistas, a ampla maioria (99\%) avaliou de forma positiva a participação, sendo que $94 \%$ dos participantes recomendariam o curso a outros colegas. Os autores da pesquisa identificaram, em muitas falas de cursistas, que o curso foi fundamental para uma mudança pessoal em relação à temática.

Teixeira (2014), em sua pesquisa de doutorado, também demonstra as transformações sobre o pensamento dos estudantes a respeito de gênero e sexualidade a partir da experiência formativa do GDE. A autora identificou que, quando as cursistas entram em contato com os conteúdos da formação, abrem-se espaços para "desestabilizar saberes e práticas que se encontram naturalizados em nossa sociedade e podem permitir a emergência de outras formas de compreender a sexualidade e as questões de gênero no espaço escolar" (p. 143).

Devido à importância dessa política pública de formação de professores, esta pesquisa se propôs a: identificar as contribuições do GDE para a formação de profissionais da educação básica; identificar as histórias/memórias das participantes no que se refere a suas trajetórias de educação sexual e a relação delas com a escola; e identificar as contribuições do GDE para a transformação das concepções de gênero e sexualidade.

\section{Procedimentos da pesquisa}

O curso mencionado foi oferecido na modalidade de Ensino a Distância pelo Instituto Estudos de Gênero (IEG/UFSC) para todo o Estado de Santa Catarina. As turmas foram oferecidas em quatro diferentes polos que ficam em diversas regióes de Santa Catarina, sendo que no Polo de Florianópolis, local em que o IEG está situado, houve quatro outras turmas. O curso foi organizado em seis módulos, que contemplaram as seguintes temáticas: educação a distância, gênero, raça, sexualidades, religião, deficiência e metodologia de ensino.

Quanto à abordagem, a pesquisa realizada é caracterizada como qualitativa. Para alcançar os objetivos propostos, foi realizado um grupo focal com nove (9) participantes do curso. O encontro com o grupo focal ocorreu na modalidade presencial em uma sala de aula da Universidade em que ocorreram os encontros presenciais.

\section{Participantes da pesquisa}

Participaram do estudo nove (9) pessoas, das quais oito (8) atuavam na rede pública de ensino no estado de Santa Catarina e uma era militante do Movimento LGBT. Todas estavam regularmente matriculadas em um dos polos em que o curso de Especialização em Gênero e Diversidade na Escola foi oferecido, haviam concluído todas as disciplinas do curso e tinham disponibilidade para irem até o local em que a reunião do grupo focal ocorreu. A descrição das participantes será apresentada em uma tabela no item referente aos resultados. 


\section{Instrumento e procedimentos de coletas de dados}

O encontro do grupo focal foi realizado em um sábado, a partir das 9 h30min da manhã, em uma sala de apoio do Departamento de Psicologia da Universidade Federal de Santa Catarina. A partir da chegada de todos os integrantes, foi realizada uma explicação sobre os objetivos da pesquisa. Eles já haviam assinado o termo de consentimento previamente, ainda assim o termo foi lido mais uma vez. O encontro do grupo focal ${ }^{1}$ durou cerca de 120 minutos e foi utilizado um roteiro aberto para que a discussão fosse produzida a partir dos relatos que as estudantes do grupo traziam de suas memórias sobre o tema (GESSER; NUERNBERG; Maria TONELI, 2012). O material foi gravado em vídeo e também em áudio com o notebook que ficou localizado à frente do grupo, disposto em meia lua, de forma que todas e todos aparecessem de forma clara em frente à câmera.

\section{Considerações éticas}

O Comitê de Ética de Pesquisa com Seres Humanos (CEPSH) do Centro de Hematologia e Hemoterapia de Santa Catarina - HEMOSC - avaliou o projeto e aprovou-o sob Protocolo n. 9231 de 16 de junho de 2015 (CAAE: 41736015.0 .0000 .0110 ). Nesta pesquisa foram garantidos os princípios éticos indicados pela Resolução 466/12 do Conselho Nacional de Saúde. Os Termos de Consentimento Livre e Esclarecido com as informações sobre a pesquisa foram lidos e assinados por todos os participantes. Todos os nomes foram substituídos por questões de sigilo.

\section{Análise do material}

Para o tratamento dos dados do grupo focal foi utilizada a análise de conteúdo do tipo categorial que, conforme Lawrence BARDIN (2000), remete a uma operação de "desmembramento do texto em unidades, em categorias segundo reagrupamentos analógicos" (p. 153), o que possibilita a obtenção de categorias simbólicas para a explicação das falas das pessoas entrevistadas.

Os dados foram sistematizados em categorias e analisados qualitativamente de acordo com os conteúdos obtidos nas entrevistas. Após essa etapa, os dados foram distribuídos em categorias definidas a posteriori. A partir dessa identificação dos sentidos de cada categoria, elas foram devidamente agrupadas e relacionadas com a teoria.

\section{Apresentando os resultados}

Será apresentada, a partir de agora, uma breve descrição dos sujeitos da pesquisa (Quadro 1). Foram levantadas questões como idade, estado civil, religião, maior formação no momento da pesquisa e tempo de trabalho com educação.

Das nove (9) participantes da pesquisa, oito (8) eram mulheres e um homem ligado ao movimento LGBT. A média de idade ficou em 43,55 anos de idade, com pessoas entre 34 e 59 anos. Com relação ao estado civil, das nove (9) pessoas, cinco (5) se revelaram casadas ou vivendo em união estável. As demais estavam solteiras, divorciadas ou viúva. Com relação à religião, apenas uma pessoa se definiu como católica, havendo um maior número de pessoas que se intitulava "espiritualistas ou espíritas" e pessoas que se definiram como ateias ou sem religião. Cinco (5) das nove pessoas participantes da pesquisa já possuíam Especialização, sendo que uma (1) delas citou a própria Especialização do GDE como tal. As demais tinham Graduação em diferentes áreas. Com relação ao tempo de magistério, apenas três (3) tinham mais de 10 anos em sala de aula. O restante das entrevistadas possuía menos de 10 anos, uma (1) professora estava dando aula há apenas seis meses e um estudante não era da área da Educação.

Em pesquisa publicada por Carrara et al. (2017) visando ao mapeamento do perfil dos estudantes do curso GDE, os autores e autoras identificaram que $86 \%$ eram mulheres, número muito próximo a grande parte de outras edições do curso no país. Como apontado pela tabela acima, a maioria dos participantes do curso investigado na pesquisa também foi mulheres. Com relação à faixa de idade, o grupo focal teve uma média de idade um pouco maior do que aquela apresentada pela pesquisa dos autores, apesar de haver no grupo cinco (5) pessoas com idade entre 30 e 40 anos. Outra diferença que foi notada é que apenas uma (1) das entrevistadas se autodeclarou como católica, sendo um número maior de pessoas que se declarou como espírita e um número considerável de pessoas que se disse sem religião. Aqui talvez seja possível identificar que há certo constrangimento em pessoas que, mesmo que tenham identificação com religiões "cristãs", apresentem dificuldade de se posicionar devido a posturas conservadoras em relação à discussão de gênero e sexualidade. Assim, definir-se como cristão acaba sendo uma posição não "confortável", já que o conteúdo do curso é considerado "polêmico" por estas religiões. Outros

\footnotetext{
${ }^{1}$ Agradecimento especial à acadêmica Fernanda Mendes, que auxiliou na coleta de dados e transcrição dos grupos
} focais. 
dados acabam sendo próximos aos apresentados pelo estudo de Carrara et al. (2017). Portanto, um número considerável (cinco (5) dos nove (9) participantes) possuía Pós-Graduação. Mas a pesquisa apresentou um número maior de professores atuantes em sala de aula que a pesquisa dos autores acima. Apenas um (1) dos participantes não era profissional da Educação.

Quadro 1 - apresentação das participantes e do participante da pesquisa

\begin{tabular}{|c|c|c|c|c|c|c|}
\hline Sujeito & Seso & Idade & Estado eivîl & Religiño & $\begin{array}{l}\text { Maior } \\
\text { formaçalo }\end{array}$ & $\begin{array}{l}\text { Tempo que } \\
\text { traballha em } \\
\text { educaça }\end{array}$ \\
\hline EI & H & 36 & Casado & Ateu & Gestâo em TI & $\begin{array}{c}\text { Niso trabalha na } \\
\text { cdocaçio }\end{array}$ \\
\hline E2 & M & 32 & Casada & Expirifualista & $\begin{array}{l}\text { Graduaçlio cm } \\
\text { Artes cểnicas }\end{array}$ & 4 anos \\
\hline E3 & M & 58 & Viưva & Espirita & $\begin{array}{c}\text { Especializaçio } \\
\text { GDE }\end{array}$ & 35 anos \\
\hline E4 & M & 59 & Casada & Nenhuma & Especializaçio & 14 anos \\
\hline E5 & M & 39 & Solteira & Espirita & Especializaçio & 7 anos \\
\hline E6 & $M$ & 42 & Solteira & Indefinida & Pós-doutorndo & 16 anos \\
\hline ET & M & 54 & Divorciada & Católica & $\begin{array}{l}\text { Graduaçìo } \\
\text { Lingua } \\
\text { portuguesa }\end{array}$ & 6 ancos \\
\hline E8 & M & 38 & Casada & $\begin{array}{l}\text { Sem } \\
\text { religiẫo }\end{array}$ & $\begin{array}{l}\text { Especialista } \\
\text { Educaçầo } \\
\text { especial }\end{array}$ & 6 anos \\
\hline E9 & M & 34 & $\begin{array}{l}\text { Unilio } \\
\text { estivel }\end{array}$ & Natureza & Licenciatura & Semestre anterior \\
\hline
\end{tabular}

\#PraCegoVer O quadro mostra a lista dos participantes da pesquisa com as seguintes informações e na seguinte sequência: identifi-cação da/o entrevistada/o, sexo, idade, estado civil, religião, maior formação e tempo que trabalha em educação: $\mathrm{El}$, homem, 36 anos, casado, ateu, gestão em Tl e não trabalha na educação; E2, mulher, 32 anos, casada, espiritualista, Graduação em Artes Cênicas, quatro anos; E3, mulher, 58 anos, viúva, espírita, Especialização GDE, 35 anos; E4, mulher, 59 anos, casada, nenhuma, Especialização, 14 anos; E5, mulher, 39 anos, solteira, espírita, Especialização, 7 anos; E6, mulher, 42 anos, solteira, indefinida, Pós-Doutorado, 16 anos; E7, mulher, 54 anos, divorciada, católica, Graduação Língua Portuguesa, 6 anos; E8, mulher, 38 anos, casada, sem religião, especialista em Educação Especial, 6 anos e E9, mulher, 34 anos, união estável, natureza, Licenciatura, semestre anterior.

A seguir apresentaremos as categorias encontradas a partir do grupo focal.

\section{Memórias da história da educação sexual e a vivência das práticas educativas}

Nesta seção serão apresentadas questões ligadas às memórias das entrevistadas sobre suas vivências relativas às suas sexualidades e suas relações, tanto no que tange à infância e à adolescência quanto com os processos de escolarização. Compreende-se aqui memória conforme Ecléa BOSI (1994), que a define a partir de um caráter dinâmico e político no qual a memória é uma reconstrução dos fatos e passagens vivenciadas; ela vem por meio das imagens das ideias, sempre mediadas pelo presente, através da capacidade e consciência que a pessoa tem do fato na atualidade. Assim, buscamos resgatar as perspectivas pessoais das entrevistadas e do entrevistado a respeito dos eventos que constituíram suas relações com as discussões tanto de gênero quanto de sexualidade, tendo as vivências dos participantes na escola como referência. 


\section{Gênero e sexualidade e a relação com a escola}

Das nove (9) pessoas entrevistadas, apenas quatro (4) se posicionaram sobre a temática. Aquelas e aquele que abordaram o tema, porém, trouxeram as primeiras lembranças sobre sexualidade e gênero a partir de falas que remeteram a uma experiência de "restrição", "erro" e "diferenciação". Uma das entrevistadas citou uma situação de não aceitação por parte de sua família em relação à homossexualidade do seu irmão. Segue uma fala que relata esta situação: "Errado [em relação à sexualidade]. Eu lembro quando eu era criança, meu pai deixava eu brincar com meninos, eu sempre tive muitos amigos, mais meninos do que meninas (E2)".

Sobre essa questão, não houve uma participação muito significativa de todas as participantes, mas de maneira geral as pessoas concordavam assertivamente com a cabeça a partir das falas das(do) colegas(colega). As principais respostas das entrevistadas denotam uma corriqueira diferenciação entre homens e mulheres, trazendo aqui as clássicas diferenciações na criação pela família. Outro ponto importante é a ressalva da "proibição" em falar de tal assunto. O que foi bem presente é que a diferenciação entre "meninos" e "meninas" se dá não somente através das palavras que ambos podem falar, mas também dos espaços a que podem ir ou frequentar. Além disso, também ficou presente a ideia de algumas entrevistadas do controle sobre suas condutas, ou ainda o que poderiam ou não fazer com seus corpos; segundo os depoimentos obtidos, estas imposições se davam exclusivamente por elas serem mulheres.

Podemos pensar essas questões como sendo cruciais para a constituição daquilo que se caracteriza como relações de gênero. Segundo Cristina WOLFF e Rafael SALDANHA (2015), as relações de gênero são engendradas nas relações sociais, com suas multiplicidades de marcadores, sejam eles raciais, de classe ou mesmo de geração, entre tantos outros que podem existir. Assim, essa constituição se faz de forma histórica e social, com expectativas relativas a cada um dos sexos e, consequentemente, aos "gêneros" que se espera que expressem.

Dessa maneira, as proibições da sexualidade são formas de delimitação daquilo que se espera de um corpo "generificado". Com isso, constituem-se lugares específicos e não lugares, os quais corroboram para que as mulheres e os homens se constituam a partir desses marcadores específicos. Em decorrência de uma sociedade patriarcal como a nossa, alguns lugares destinados aos homens já se encontram resguardados a partir das suas características sexuais específicas, mas que depois precisam ser correspondidas através do gênero que será apresentado socialmente. $\mathrm{E}$, para isso acontecer, várias instituições são importantes, mas uma delas especificamente é crucial: a família. Segundo Guilherme CARVALHO e Marcília MENDES (2015), a família socializa valores característicos da masculinidade e da feminilidade, assim como introduz conhecimentos, específicos ou não, sobre a sexualidade que entende ser pertinente à socialização dos filhos e das filhas, de uma forma a controlar "imaginariamente" o processo de subjetivação dos seus descendentes.

Outros aspectos que ficaram aparentes nos relatos das nossas entrevistadas e do nosso entrevistado foram questões atreladas às separações entre os sexos, por meio das roupas e dos disciplinamentos dos corpos e através das brincadeiras, caracterizadas por serem de meninos ou de meninas. Segue abaixo um relato que exemplifica essa questão:

[As diferenças] de uniforme diferente, usava saia, vestidinho, os meninos tinham calça, bermuda, podiam correr bastante, fazer as coisas [...]. O esporte... no colégio que eu estudei tinha educação física separada. As meninas tinham que fazer com as meninas e os meninos com os meninos, juntavam duas turmas e ficavam as meninas com uma professora e os meninos com um professor (E6).

As discussões sobre o disciplinamento dos corpos atribuído a partir das diferenças de sexo e, consequentemente, de gênero, têm sido amplamente exploradas por diversas autoras (Judith BUTLER, 1999; Cristina REIS; Marlucy PARAísO, 2014). Pode-se perceber, assim, pelas respostas das entrevistas do grupo, que de alguma maneira a constituição de uma generificação a partir do sexo se roteirizava, utilizando aqui a ideia de roteiros sexuais (John GAGNON, 2006) para elas e eles, o que se apresentaria como formas de ser e estar no mundo caracteristicamente como algo de meninos e de meninas. O interessante é que estas "performances" roteirizadas vão desde roupas, expressões corporais e brincadeiras, o tempo todo mediadas em casa pelas famílias e na escola pelos professores.

Uma das falas que chamou atenção foi a de um dos participantes que trouxe a sua experiência da escola e do isolamento sofrido em virtude de sua homossexualidade.

[...] fui ter consciência da minha homossexualidade mesmo com 15 anos de idade, desejo mais forte assim com 13, 14. Quando eu era mais novo já não gostava de ficar com os meninos, não gostava de jogar futebol e fazer todas essas coisas, ficava sempre de lado, me chamavam de bichinha, aquelas coisas, então não convivia com os meninos. [...] [Contexto] De isolamento, eu era bem isolado no intervalo, nas coisas assim, bem na minha, assim, tímido (E1). 
As características tipificadas de gênero e sua respectiva identificação binária com cada uma delas fazem com que a não correlação entre sexo biológico e gênero traga um estranhamento primeiro por parte dos adultos que, como já apontado anteriormente, vai "tipificar" esse suposto "desacordo" com as crianças. Neste caso, poderia se compreender aquilo que Bader SAWAIA (1999) identificaria como sofrimento ético-político, causado pelo sentimento reiterado de não pertencimento ou, mesmo, como a própria autora ressalta, "a vivência particular das questões sociais dominantes em cada época histórica [...]. Sofrimento que surge da situação de ser tratado como inferior, subalterno, sem valor, apêndice inútil da sociedade" (p. 56). A solidão na escola talvez seja uma das marcas mais visíveis desse processo.

\section{A dificuldade de as escolas auxiliarem no reconhecimento dos direitos sexuais e reprodutivos}

Outra questão que foi apontada pelas pessoas entrevistadas foi relacionada à dificuldade de as escolas contribuírem com a construção de processos educativos voltados ao reconhecimento dos direitos sexuais e reprodutivos. Esse ponto ficou mais visível no que se refere ao direito que cada pessoa deve ter de poder expressar o seu gênero e a sua sexualidade. As falas foram muito voltadas a uma crítica às instituições de ensino por elas não abordarem essas questões. Primeiro foi perguntado o que elas lembravam sobre o que aprenderam a respeito das temáticas "gênero e sexualidade" em seus tempos estudantis. Em seguida, foi abordado como elas percebiam essa temática nos dias de hoje.

Todos os participantes destacaram que, durante suas trajetórias escolares, os assuntos de gênero e sexualidade estiveram praticamente ausentes. Quando essas temáticas eram discutidas, isso acontecia por meio de uma abordagem que não atendia às suas necessidades. Dessa forma, ao serem questionados sobre o que aprenderam na escola, a maior parte do grupo afirmou "nada".

Fica muito visível, tanto na fala das entrevistadas como na do entrevistado, o quanto a escola não foi uma mediação em seus tempos de formação para uma educação onde se problematizassem as questões sobre direitos sexuais e reprodutivos. Mas houve uma questão que foi muito citada por alguns dos entrevistados, que foi o atrelamento das discussões ao conhecimento biológico e ao aparelho reprodutor sexual. Quando apresentado, esse assunto vinha vinculado ao conhecimento anatômico. Segue uma fala a respeito:

Mas nunca fala do orgasmo feminino, do prazer, nunca fala a respeito disso e até os métodos contraceptivos assim, mostra, mostrava como colocar a camisinha no lugar e, no caso da camisinha feminina, mostra lá a camisinha na vagina transparente sem corpo, mas no caso da camisinha feminina mostra simplesmente a camisinha feminina, nem sabe como usar. [...] Sim! Sempre associado a isso! [biologia] Eu, pensando na minha formação, acho que a escola até não contribui, ela contribui pra reforçar os estereótipos (E6).

As estudantes apontaram a ênfase dada na escola às discussões sobre o corpo, a biologia e a prevenção de doenças, mais do que uma ampliação sobre gênero e sexualidade em seu conceito mais abrangente e também inclusivo. O tema da diversidade sexual foi ainda menos citado como um elemento importante para suas formações. Aqui é possível lembrar discussões clássicas de Simone de BEAUVOIR (1991) e Butler (1999), nas quais se pode perceber como a biologia presentifica a desigualdade nas relações entre homens e mulheres com base em uma hierarquia constituída a partir do gênero. Além disso, a pesquisa de Gesser, Oltramari e Panisson (2015) apontou para uma predominância na redução das discussões de gênero e sexualidade na escola aos fatores biológicos, tendo os aspectos reprodutivos uma centralidade muito grande para a discussão. E isso contribui, como indicou uma das entrevistadas, para que os estereótipos se solidifiquem, tornando-se ainda mais presentes no cotidiano e na vida das e dos estudantes.

Outro ponto interessante que apareceu é que, mesmo a escola não trazendo as discussões de gênero e sexualidade para o interior da sala de aula, tais discussões são buscadas a todo o momento pelos estudantes. Elas e eles buscam respostas para as dúvidas, que são muitas, e a escola não se atreve ou não se encoraja a responder. A seguir é apresentado um exemplo da experiência que as professoras têm sobre essa realidade com seus estudantes.

Eu levo meus alunos na biblioteca por causa da disciplina de português [...] e agora eu me lembrei. Tinha um grupinho escondidinho lá num cantinho da biblioteca e fui ver o que eles estavam fazendo. Fui lá e eles estavam olhando os livros de educação sexual, estavam escondidinhos para fazer pesquisa [...]. "Vamos conversar!" (E3).

Outro ponto que ficou muito evidente na pesquisa foi o relacionado ao movimento da escola de abdicar das discussões coletivas relacionadas a gênero e sexualidade quando há determinados educadores que têm um comprometimento pessoal com as temáticas. Isto faz com que muitas vezes esses docentes sejam demandados a tomarem a frente destas discussões, o que provoca uma isenção de responsabilidade dos demais profissionais da escola. Podemos ver estas questões a partir da fala de uma das entrevistadas: 
Eu já escutei isso de colegas da biologia, "chega no ensino médio a gente não tem conteúdo de corpo humano, tem lá fisiologia, fisiologia animal. De repente, a gente vai lá e coloca alguma coisa, fala sobre genética, fala sobre reprodução, alguma coisa". E eu tive colegas assim que não [...], mas assim era pra falar sobre doenças sexualmente transmissíveis e não se sentiam à vontade porque inevitavelmente tinha que falar sobre sexo, né! É de professor (E6).

As professoras trouxeram de maneira geral em suas falas que, tanto pelo interesse pela área quanto pela formação específica, isto fazia delas protagonistas principais das discussões sobre o assunto em sala de aula ou mesmo na escola. Pode-se compreender essas falas a partir de dois aspectos específicos. O primeiro deles se refere à ausência da discussão sobre gênero na formação universitária (ALTMANN, 2013), o que faz com que alguns professores se sintam menos "capacitados" a discutir tal temática em sala de aula. E o segundo, que talvez seja o mais interessante, está relacionado ao caráter subjetivo e identitário relativo a essa temática.

Como já apontado por Zibetti e Souza (2007), os saberes docentes são constitutivos das práticas pedagógicas em salas de aula e, como se percebe, elas estão ancoradas em hábitos e estruturas compreendidos como estáveis no meio social (CARVALHO, 2010). Ou seja, as informações mostraram que existem nas experiências concretas apresentadas pelas participantes elementos que as fazem se comprometerem com as questões de gênero e sexualidade, algo que as toca e faz sentido em suas vidas. Pode-se pensar que a motivação para estas professoras ocuparem os lugares de responsáveis pela discussão na escola se dá tanto pelo "vazio" deixado pelos colegas, que não se habilitam a fazê-la, quanto pela sua identificação e militância pela discussão. Este talvez seja o motivo mais significativo para elas.

\section{Formação pelo GDE}

Neste item serão apresentadas questões ligadas às representações das entrevistadas e do entrevistado a respeito de seus conhecimentos sobre gênero e sexualidade antes da formação pelo GDE e quais as principais mudanças promovidas para sua formação a partir do curso. As cursistas e o cursista trouxeram as suas impressões sobre o processo de formação promovido pelo GDE:

Antes do GDE, mas a diferença realmente é no conteúdo, porque nunca fui de ler, eu sempre fui da área técnica de TI. Ter esse contato com as humanas, que eu sempre tive vontade, o GDE abriu minha cabeça totalmente diferente no sentido de estudos de conteúdo, o formato, né? Fora as transversalidades principalmente, tratar raça e etnia, foi uma das matérias mais difíceis pra mim, deficiência foi superbom, foi a última, foi a mais corrida, mas eu gostei também (E1).

No discurso das cursistas, foi muito destacado quanto o GDE foi desvelador de conhecimentos que antes eram percebidos como "naturais" e foram desmistificados. A formação do curso foi identificada como importante para superar conhecimentos antes tidos como "naturais". Vários conteúdos - não somente de gênero como também das discussões étnico-raciais e, principalmente, sobre deficiência, temáticas também abordadas pelo curso - foram considerados significativos para suas formações. Elas compreenderam que o curso deu subsídios para mudanças substanciais em suas práticas pedagógicas e mesmo de vida. Houve um processo de desnaturalização do conhecimento que até então tinham e iniciaram uma leitura transversal sobre as categorias estudadas e suas próprias vivências. Resultado semelhante apareceu em estudos de Barbosa (2014), Teixeira (2014), Rosa (2016) e Carrara et al. (2017).

\section{Uma experiência militante}

Esta foi uma categoria recorrente na fala das estudantes, o caráter feminista ou da sua experiência subjetiva ou do curso. O curso foi percebido como um propulsor desta identidade feminista apontada pelas entrevistadas.

Você é feminista sim, você é bem feminista [disse o marido]. Não sou! [E5] É sim! [disse o marido]. Uma vez a gente até discutiu assim, o que é ser feminista, radical! Nunca me achei feminista, e depois que comecei a fazer o GDE percebi coisas, que tinha coisas do feminismo em mim e eu não sabia [E5].

O curso foi identificado como um vetor importante para a constituição daquilo que as pessoas participantes nomearam "ser feminista", mas ainda assim houve questões interessantes para discutir. Por exemplo, na fala das entrevistadas, expressaram que, de alguma forma, haviam interiorizado uma ideia do que consideravam "ser feminista". Aqui mais uma vez a experiência subjetiva dos saberes docentes anteriores (ZIBETTI; SOUZA, 2007) pode ser articulada com um conceito de correspondência identitária. Entende-se aqui a identidade, a partir de Carlos NAUJORKS e Marcelo SILVA (2016), como

[...] uma construção social de significados, sentimentos e emoções associados ao autorreconhecimento e ao reconhecimento dos outros. Essa construção é tanto singular (própria 
a um indivíduo particular) quanto coletiva (própria a um conjunto de indivíduos). Enquanto construção singular, os significados e sentimentos são apreendidos cognitivamente e vivenciados emocionalmente (p. 139).

É permitido identificar, como já descrito anteriormente, que existe sim uma intencionalidade na discussão sobre a temática não especificamente sobre "feminismo", mas sobre igualdade nas relações de gênero, como foi demonstrado pelas entrevistadas e pelo entrevistado e na pesquisa de Graupe e Grossi (2014). Ou seja, as cursistas já tinham interesse ou identificação anterior com a temática. De alguma maneira, pode-se dizer que existe uma construção de sentido a partir das experiências singulares das entrevistadas. Existe em suas falas uma elaboração coletiva que elas encontram na perspectiva política feminista construída com base nos conhecimentos do curso.

É possível entender, a partir do conceito de correspondência identitária (SNOW; MCADAM, citados por NAUJORKS; SILVA, 2016), que existe uma relação entre os processos identitários do sujeito e uma identidade do grupo. No caso do GDE, esta está associada com um posicionamento comprometido com as lutas e a agenda do movimento feminista. Com isso, acontece o que os autores chamam de congruência entre identidade individual e coletiva.

Vale ressaltar que essa congruência se constitui como uma tarefa nem sempre fácil para algumas estudantes protagonistas do curso. Em uma das falas, ficou marcado o quanto esse conhecimento que produz engajamento e transforma pode trazer inclusive situações de desconforto pessoais. Segue abaixo uma fala que aponta essa questão:

Como eu falei, tô há pouco tempo. Mas tenho certeza e nem sou eu, não tem como você ter feito esse curso, a não ser que você seja um hipócrita, que você não vai mudar tua maneira de ser, tá numa roda de amigos mesmo quando você tá, quando você tá como educador principalmente, você tem obrigação de se posicionar assim, ao menos esclarecendo coisas (E9).

A formação do GDE aparece como um lugar onde as cursistas e o cursista se sentiram empoderadas(emporado) através das reflexões que o curso Ihes trouxe. Além disso, o curso apontou sentidos para suas práticas docentes, assim como embasamento teórico. Ademais, também se configurou como um espaço que as(o) auxiliou a perceber as violências generificadas das quais foram vítimas. Muitas vezes também foi relatada a solidão de um trabalho com outras pessoas que não compartilham os mesmos posicionamentos políticos e teóricos que elas(ele) possuíam. Desta forma, a militância vem novamente em cena para trazer os aspectos mais importantes do trabalho que presume uma transformação social nas relações de gênero mobilizadas principalmente pelo interior da escola. É possível compreender, a partir de Hélène GUÉTAT-BERNARD e Nathalie LAPEYRE (2017) que, mesmo partindo das discussões polêmicas sobre o "empoderamento", tomadas de assalto pela questão do neoliberalismo, existe uma dimensão importante trazida pelo movimento feminista que é a capacidade de desenvolvimento de uma consciência crítica dos problemas que envolvem homens e mulheres, pois este conceito traz para junto de si uma leitura crítica, dos discursos, práticas e ideologias e quanto ele pode estruturar estratégias de mudanças em grande escala.

Assim, as falas apontaram que a formação oferecida pelo GDE conseguiu não somente passar os conhecimentos teóricos sobre os temas abordados para a prática profissional. Ela também contribuiu para que os participantes pudessem compreender suas próprias histórias e processos de constituição como sujeitos generificados e sexualizados. Além disso, também foi constitutiva da identidade individual e coletiva deste grupo de mulheres e homens que constituíram este grupo.

\section{Considerações finais}

Com relação às histórias e memórias das participantes relacionadas à educação sexual, foi identificado no estudo que essas foram fortemente constituídas pelos binarismos sociais de gênero reproduzidos nas famílias das pessoas participantes, os quais produziam como efeitos diferenciações entre meninos e meninas e restrições às meninas. Especificamente quando a questão foi a orientação sexual, esta foi ainda mais descrita como um elemento de difícil aceitação, seja pela família, seja pela escola. A palavra "proibição" foi enunciada por algumas participantes e muito acompanhada assertivamente por outras que ficavam caladas e ouvindo atentamente.

Em relação às contribuições da escola para a construção das concepções de gênero e sexualidade dos participantes, foi constatado que essa instituição operou principalmente como um espaço de normatização e restrição das vestes dos corpos e comportamentos. A separação entre meninos e meninas nos espaços e atividades foi citada pelas professoras. Dessa forma, a escola corroborou a constituição de uma roteirização das formas de estar naquele espaço, a partir das divisões de gênero. Assim, as participantes citaram que houve uma certa complementaridade entre a escola e as famílias no estabelecimento das diferenças entre meninos e meninas. As informações obtidas também evidenciaram que, no que se refere a conhecimentos sobre gênero e sexualidade fornecidos pelas escolas em que as participantes estudaram, esses eram conteúdos predominantemente vinculados aos aspectos biológicos, corroborando a naturalização de um 
discurso que reduz a sexualidade aos aparelhos reprodutores e com um viés meramente anatômico. Com isto, a diversidade sexual, principalmente quanto ao campo atrelado às discussões sobre orientação sexual, não foi abordada em suas histórias.

Sobre as contribuições que o curso Gênero e Diversidade na Escola trouxe às pessoas participantes do estudo, as informações obtidas evidenciaram que o curso auxiliou para que elas desmistificassem diversos conceitos previamente aprendidos ao longo de suas histórias, os quais eram predominantemente associados à biologia. E isto não aconteceu somente com as discussões sobre gênero e sexualidade, mas com relações étnico-raciais e deficiência. Em relação a essa última categoria, destaca-se o caráter inovador do curso de Especialização em Gênero e Diversidade na Escola oferecido em Santa Catarina, que até a presente data foi o único no país a trazer essa discussão, incorporando deficiência como uma categoria de análise, como propõem Gesser, Nuernberg e Toneli (2012). Assim, muitas das professoras participantes do grupo salientaram que esta foi uma das discussões que mais contribuiu em suas formações.

O curso trouxe em suas histórias/memórias um discurso militante que valeu às cursistas, em várias ocasiões, inclusive por familiares, o epíteto de "feministas". E vale dizer que a maioria delas, a partir do curso, começou a se reconhecer como tal. Também vale dizer que, para algumas professoras, este novo lugar de (re)posicionamento frente às relações de gênero tem ocasionado, muitas vezes, tensões no âmbito privado familiar.

Os resultados da pesquisa também indicaram que o curso de alguma forma potencializou estas mulheres que participaram dele. Mas algumas questões podem ser pensadas. Até que ponto o curso não retomou algumas questões que já vinham há tempo na história destas mulheres se desenvolvendo, como estranhar esse lugar marcado pelas diferenças entre homens e mulheres? Ou ainda: é possível que esse curso tenha uma capacidade de empoderamento e desenvolvimento de uma atitude militante daqueles e daquelas que o cursam? Cabem, além disso, outras pesquisas sobre a temática para que essas questões possam ainda ser exploradas. O que se pode dizer dos resultados desta pesquisa é que os conhecimentos do curso qualificaram as pessoas participantes com relação à temática da diversidade na escola. Além disso, fizeram com que as/o participantes da pesquisa refletissem sobre suas práticas e suas vidas, reconfigurando suas experiências e fazendo com que estas possam ser transformadas quando em suas práticas no contexto escolar. Espera-se que outros cursos como esse continuem sendo desenvolvidos para o avanço do referido campo de conhecimento.

\section{Referências}

ALTMANN, Helena. "Diversidade sexual e educação: desafios para a formação docente". Sexualidad, Salud y Sociedad - Revista Latinoamericana, n. 13, p. 69-82, abril 2013.

BARBOSA, Jaqueline Aparecida. Curso 'gênero e diversidade na escola': influência na prática profissional segundo ex-cursistas do Distrito Federal Brasília -DF. 2014. Especialização (Gestão de Políticas Públicas em Gênero e Raça) - Universidade de Brasília, Brasília, DF, Brasil.

BARDIN, Lawrence. Análise de Conteúdo. Lisboa: Edições 70, 2000.

BARROS, Sulivan Charles. "Gênero e Diversidade na Escola em Goiás: relato de experiência". Revista Café com Sociologia, v. 6, n. 1, p. 201-212, jan./abr. 2017.

BEAUVOIR, Simone de. O segundo sexo. Rio de Janeiro: Nova Fronteira, 1991.

BELLO, Melissa C.; SANTOS, Dayana B. C. "Gênero e diversidade na escola: formação de professoras/ es e os desafios na construção de práticas curriculares de enfrentamento ao preconceito e à discriminação no âmbito escolar no Paraná". In: FAZENDO GÊNERO: DIÁSPORAS, DIVERSIDADES, DESLOCAMENTOS, 9, 2010, Florianópolis, Instituto de Estudos de Gênero. Anais... Florianópolis: IEG, 2010. p. 1-6.

BORGES, Zulmira N.; MEYER, Dagmar E. S. "Limites e possibilidades de uma ação educativa na redução da vulnerabilidade à violência e à homofobia". Ensaio: Avaliação e Políticas Públicas em Educação, v. 16, n. 58, p. 59-76, 2008.

BOSI, Ecléa. Memória e sociedade. 5. ed. São Paulo: Companhia das Letras, 1994.

BUTLER, Judith. "Corpos que pesam: sobre os limites discursivos do 'sexo'”. In: LOURO, Guacira, L. (Org). O corpo educado. Belo Horizonte: Autêntica, 1999. p. 151-172.

CABRAL, Paulo Sérgio. Qual o conceito de gênero na perspectiva docente? 2016. Trabalho de Conclusão (Especialização em Gênero e Diversidade na Escola) - Universidade Federal do Paraná, Setor Litoral/UFPR, Itajaí, SC, Brasil. 
CARRARA, Sérgio; NASCIMENTO, Marcos; DUQUE, Aline; TRAMONTANO, Lucas; PEREIRA, Maria Elisabete. Gênero e diversidade na escola: avaliação de processos, resultados, impactos e projeções. Rio de Janeiro: CEPESC, 2017.

CARVALHO, Maria Eulina Pessoa de. "Gênero é um conceito complexo e de difícil sensocomunização. Considerações a partir de uma experiência de formação docente". Instrumento: Revista de Estudo e Pesquisa em Educação, Juiz de Fora, v. 12, n. 2, p. 75-87, jul./dez. 2010.

CARVALHO, Guilherme Paiva de; MENDES, Marcília Gomes. "Gênero e políticas educacionais no Brasil”. Cadernos Espaço Feminino, Uberlândia, v. 21, n. 1, p. 7-23, jan./jun. 2015.

DINIS, Nilson Fernandes. "Educação, relações de gênero e diversidade sexual". Educação \& Sociedade, Campinas, v. 29, n. 103, p. 477-492, maio/ago. 2008.

FREIRE, Nilcéa; SANTOS, Edson; HADDAD, Fernando. "Apresentação". In: BARRETO, Andreia; ARAÚJO, Leila; PEREIRA, Maria Elisabete (Org.). Gênero e Diversidade na Escola: formação de professores em Gênero, orientação sexual e relações étnico-raciais. Caderno de Atividades. Rio de Janeiro: CEPESC, 2012. p. 9-10.

GAGNON, John. Uma interpretação do desejo: ensaios sobre o estudo da sexualidade. Rio de Janeiro: Garamond, 2006.

GESSER, Marivete; OLTRAMARI, Leandro C.; CORD, Denise; NUERNBERG, Adriano H. "Psicologia escolar e formação continuada de professores em gênero e sexualidade". Psicologia Escolar e Educacional, v. 16, n. 2, p. 229-236, 2012.

GESSER, Marivete; NUERNBERG, Adriano H.; TONELI, Maria J. F. "A contribuição do modelo social da deficiência à Psicologia Social”. Psicologia e Sociedade, v. 24, n. 3, p. 557-566, 2012.

GESSER, Marivete; OLTRAMARI, Leandro C.; PANISSON, Gelson. "Docência e concepções de sexualidade na educação básica". Psicologia \& Sociedade, v. 27, n. 3, p. 558-568, 2015.

GRAUPE, Mareli. "Gênero, diversidade e sexualidades: formação continuada de professor@s." In: SEMINÁRIO INTERNACIONAL FAZENDO GÊNERO, 10, 2013, Florianópolis, Instituto de Estudos de Gênero. Anais... Florianópolis: IEG, 2013. p. 1-12. Disponível em http://www.fg2013.wwc2017.eventos.dype. com.br/resources/anais/20/1373462842_ARQUIVO_texto-Mareli-Genero.pdf. Acesso em 10/08/2017.

GRAUPE, Mareli Eliane; GROSSI, Miriam Pillar. "Desafios no processo de implementação do curso gênero e diversidade na Escola (GDE) no Estado de Santa Catarina". Poiésis, Tubarão, v. 8, n. 13, p. 104-125, jan./jun. 2014.

GREBINSKY, Raquel Caterine. Nem "bordel homoafetivo", nem "política de canalha": um estudo sobre as políticas públicas de gênero e sexualidade no congresso nacional. 2016. Especialização (Gênero e Diversidade na Escola) - Universidade Federal de Santa Catarina, Florianópolis, SC, Brasil.

GUÉTAT-BERNARD, Hélène; LAPEYRE, Nathalie. "Les pratiques contemporaines de l'empowerment: pour une analyse des interactions entre pratiques et théories, individu.e.s et collectifs". Cahiers du Genre, n. 63, p. 5-22, 2017.

KAMENSKY, Andrea P. dos S. O.; WAKS, Jonas; CONCHÃO, Silmara; SILVA, Zilda B. D. Políticas e direitos: políticas públicas de formação docente em direitos humanos, gênero e diversidade na escola no Brasil (2006-2016). São Paulo: Editora Pontocom, 2016.

LOPES, Juliana Crespo; PULINO, Lucia Helena Cavasin Zabotto; BARBATO, Mariana; PEDROZA, Regina Lucia Sucupira. "Construções coletivas em educação do campo inclusiva: reflexões sobre uma experiência na formação de professores". Educação e Pesquisa, v. 42, n. 3, p. 607-623, abr. 2016.

MADUREIRA, Ana Flávia do Amaral; BRANCO, Ângela Uchoa. "Gênero, Sexualidade e Diversidade na Escola a partir da Perspectiva de Professores/as". Temas em Psicologia, v. 23, n. 3, p. 577-591, 2015.

MELLO, Luis; BRITO, Walderes; MAROJA, Daniela. "Políticas públicas para a população LGBT no Brasil: notas sobre alcances e possibilidades". Cadernos Pagu, v. 39, p. 403-429, jul./dez. 2012.

NAUJORKS, Carlos José; SILVA, Marcelo Kunrath. "Correspondência identitária e engajamento militante". Civitas, Porto Alegre, v. 16, n. 1, p. 136-152, jan./mar. 2016. 
REIS, Cristina d'Ávila; PARAÍSO, Marlucy Alves. "Normas de gênero em um currículo escolar: a produção dicotômica de corpos e posições de sujeito meninos-alunos". Revista Estudos Feministas, v. 22 , n. 1, p. 237-256, abr. 2014.

ROSA, Ana Cristina Batista de Souza. Ressignificações das aprendizagens de gênero de educadores/as no Curso de Especialização em Gênero e Diversidade na Escola. 2016. Dissertação (Mestrado) - Programa de Pós-Graduação em Educação, Universidade Federal da Paraíba, João Pessoa, PB, Brasil.

ROSSI, Célia Regina; VILARONGA, Carla Ariela; GARCIA, Osmar Arruda; LIMA, Maria Teresa Oliveira. "Gênero e Diversidade na Escola: reflexões acerca da formação continuada sobre assuntos da diversidade sexual". Contexto \& Educação, Unijuí, ano 27, n. 88, p. 6-34, jul./dez. 2012.

SAWAIA, Bader. "O sofrimento ético-político como categoria de análise da dialética exclusão/ inclusão". In: SAWAIA, Bader (Org.). As artimanhas da exclusão: análise psicossocial e ética da desigualdade social. Petrópolis: Vozes, 1999. p. 97-118.

SILVA, Fabiane M. "Educação e Docência: Um estudo sobre as relações de gênero e diversidade na escola". Revista Ártemis, v. XXII, n. 1, p. 17-31, jul.-dez. 2016.

TEIXEIRA, Fabiane Lopes. Gênero e Diversidade na Escola - GDE: investigando narrativas de profissionais da educação sobre diversidade sexual e de gênero no espaço escolar. 2014. Tese (Doutorado em Educação) - Programa de Pós-Graduação em Educação, Universidade Federal de Pelotas, Pelotas, RS, Brasil.

TOZETTI, Renata de Fátima. O curso gênero e diversidade na escola (GDE): uma análise sobre o olhar de cursistas da UFPR litoral. 2017. Dissertação (Mestrado em Desenvolvimento Territorial Sustentável) - Universidade Federal do Paraná, Setor Litoral/UFPR, Matinhos, PR, Brasil.

VENCATO, Ana Paula. "A diferença dos outros: discursos sobre diferenças no curso Gênero e Diversidade na Escola da UFSCar". Contemporânea, v. 4, n. 1, p. 211 -229, jan./jun. 2014.

VIANNA, Cláudia. "Gênero, sexualidade e políticas públicas de educação: um diálogo com a produção acadêmica". Pro-Posições, v. 23, n. 2, p. 127-143, maio/ago. 2012.

WOLFF, Cristina Scheibe; SALDANHA, Rafael Araújo. "Gênero, sexo, sexualidades: Categorias do debate contemporâneo". Revista Retratos da Escola, Brasília, v. 9, n. 16, p. 29-46, jan./jun. 2015.

ZIBETTI, Marli Lúcia Tonatto; SOUZA, Marilene Proença Rebello de. "Apropriação e mobilização de saberes na prática pedagógica: contribuição para a formação de professores". Educação e Pesquisa, São Paulo, v. 33, n. 2, p. 247-262, ago. 2007.

Leandro Castro Oltramari (leandro.oltramari@ufsc.br) é Professor Associado I da Universidade Federal de Santa Catarina. Participante do Grupo de pesquisa "Psicologia e Processos Educacionais" e participante do grupo Instituto de Estudos de Gênero. Vice-líder do grupo de pesquisa Clínica da Atenção Psicossocial e Uso de Álcool e O utras Drogas. Coordenador do Laboratório de Psicologia Escolar e Educacional.

Marivete Gesser (marivete.gesser@ufsc.br) é professora do Programa de Pós-Graduação em Psicologia da UFSC. Graduada em Psicologia, mestre em Psicologia Social pela PUC-SP e doutora em Psicologia pela UFSC. Pós-Doutorado na State University of New York/Stony Brook/NY/USA, onde atuou como Visiting Scholar estudando as contribuições dos Estudos sobre Deficiência para a atuação de psicólogos nas políticas sociais. 


\section{COMO CITAR ESSE ARTIGO DE ACORDO COM AS NORMAS DA REVISTA}

OLTRAMARI, Leandro Castro; GESSER, Marivete. "Educação e gênero: histórias de estudantes do Curso Gênero e Diversidade na Escola". Revista Estudos Feministas, Florianópolis, v. 27, n. 3, e57772, 2019.

\section{CONTRIBUIÇÃO DE AUTORIA}

Leandro Castro Oltramari: elaboração do projeto, execução da pesquisa, análise de dados e escrita do manuscrito.

Marivete Gesser: elaboração do projeto, análise de dados e escrita do manuscrito.

FINANCIAMENTO

Não se aplica

CONSENTIMENTO DE USO DE IMAGEM

Não se aplica

APROVAÇÃO DE COMITÊ DE ÉTICA EM PESQUISA

Projeto aprovado pelo Comitê de ética do HEMOSC sob Protocolo n. 9231 de 16 de junho de 2015 (CAAE:/ 41736015.0 .0000 .0110 ).

\section{CONFLITO DE INTERESSES}

Não se aplica

\section{LICENÇA DE USO}

Este artigo está licenciado sob a Licença Creative Commons CC-BY International. Com essa licença você pode compartilhar, adaptar, criar para qualquer fim, desde que atribua a autoria da obra.

HISTÓRICO

Recebido em 18/06/2018

Reapresentado em 19/11/2018

Aprovado em 04/04/2019 